\title{
A EDUCAÇÃO FíSICA E O TRABALHO EDUCATIVO INCLUSIVO
}

\author{
PHYSICAL EDUCATION AND INCLUSIVE EDUCATIONAL WORK
}

LA EDUCACIÓN FÍSICA Y EL TRABAJO EDUCATIVO INCLUSIVO

\author{
Anaís Suassuna Simões ${ }^{\star}$, Ana Rita Lorenzini ${ }^{\star}$, Rosangela Gavioli**, \\ Iraquitan de Oliveira Caminha *, Marcílio Barbosa Mendonça de Souza Júnior*, \\ Marcelo Soares Tavares de Melo*
}

\begin{abstract}
Palavras chave:
Inclusão

educacional.

Educação Física.

Ensino fundamental.

Resumo: Analisamos o trabalho educativo nas aulas de Educação Física (EF), discutindo-o na sua relação com os propósitos da inclusão de estudantes com deficiência numa escola regular privada. No geral, alinhamos a investigação com a base teórica crítico-dialética e, nesta, o método da ascensão do abstrato ao concreto elaborado por Kosik (2011). Utilizamos o estudo de caso via estudo documental (o planejamento da professora, 0 Projeto Político Pedagógico e os perfis da turma) e de campo, tendo como sujeitos: a professora, a coordenadora, a psicóloga, a diretora e 21 estudantes. Concluímos, após doze aulas observadas, que houve aproximação com a EF Crítico-Superadora, mediante adequações no planejamento das aulas, das atividades e dos materiais utilizados, visando à apropriação dos estudantes sobre o conteúdo tratado. As análises dos documentos e entrevistas explicitaram que não houve restrição à participação dos estudantes com deficiência, revelando a concretização do trabalho inclusivo.
\end{abstract}

Keywords:

Educational inclusion.

Physical Education.

Education,

elementary.

Palabras clave:

Inclusión

educacional.

Educación Física.

Educación primaria.
Abstract: We analyzed the educational work in Physical Education (PE) classes by relating it to the purposes of inclusion of students with disabilities at a regular, private school. In general, the research was in line with the critical-dialectical theoretical basis and thus with Kosik's (2011) method of rising from abstract to concrete. Case study was used via documental study (teacher's planning, Political-Pedagogical Project and the class's profiles) and field study focused on: teacher, coordinator, psychologist, principal, and 21 students. After observing 12 lessons, we found that there was approximation with CriticalOvercoming PE through adjustments in lessons planning, activities, and materials used so that students could appropriate content. Analyses of the documents and interviews showed that there was no restriction on participation of students with disabilities, pointing out that inclusive work was accomplished.

Resumen: El objetivo fue analizar la labor educativa en Educación Física (EF) en su relación con los propósitos de la inclusión de estudiantes con discapacidad en una escuela privada regular. En general, alineamos la investigación con la base teórica crítico dialéctica y, en esta, el método de lo abstracto a lo concreto de Kosik (2011). Utilizamos el estudio de caso a través del estudio documental (planificación del maestro, el Proyecto Político Pedagógico y los perfiles de los alumnos) y de campo. Tuvimos como sujetos: la profesora, la coordinadora, la psicóloga, la directora y 21 estudiantes. Concluimos, después de doce clases observadas, que hubo aproximación a la EF Crítico Superadora mediante adecuaciones en la planificación de las clases, de las actividades y de los materiales utilizados, buscando la apropiación de los estudiantes sobre el contenido tratado. El análisis de documentos y entrevistas evidenció que no hubo restricción a la participación de los estudiantes con discapacidad, revelando la concretización del trabajo inclusivo.
*Universidade de Pernambuco. Recife, PE, Brasil.

E-mail: nana_suassuna @ hotmail.com; arita@globo.com;

caminhairaquitan@gmail.com; marciliosouzaj@ @ hotmail.com; mmelo19@ hotmail.com

**Universidade de São Paulo. São Paulo, SP, Brasil.

E-mail: rosangel@usp.br

Recebido em: 29-04-2017 Aprovado em: 19-10-2017

DOI: http://dx.doi.org/10.22456/1982-8918.73009 (c) (1) (8) Licence 


\section{INTRODUÇÃO}

Entendemos que inclusão é um conceito que invoca um comprometimento político, uma mudança de atitude, tendo como objetivo a construção de uma sociedade mais justa com sujeitos críticos, livres, sendo estes com ou sem deficiência. Para tal precisamos compreender que

[...] uma pedagogia que valorize a liberdade dos indivíduos não será aquela que tenha por objetivo formar nos alunos a capacidade de adaptação à realidade local da qual fazem parte, mas sim aquela que forme nos alunos a consciência da necessidade de apropriação da riqueza espiritual universal e multifacetada (DUARTE, 2011, p.10).

Alinhar as discussões sobre inclusão com pedagogias que buscam formar estudantes conscientes de si e capazes de apreender o que está em sua volta, independentemente de suas características pessoais, se faz necessário. Os sujeitos podem se corresponsabilizar pelo processo de inclusão, mas a ação política precisa ir além dos indivíduos, buscando forças e providências nas instâncias coletivas e públicas, principalmente na educação, sobretudo, pelo fato de que as estratégias que estão sendo adotadas nas escolas vêm se mostrando insuficientes para dar conta da aprendizagem e da participação efetiva dos estudantes com deficiência, (BRITO; LIMA, 2012; FIORIN, 2011; CRUZ, 2005; ARAÚJO JÚNIOR, 2012; FALKENBACH; LOPES, 2010).

A Pedagogia Histórico-Crítica (PHC), de Saviani (2008, 2011, 2013a, 2013b), entre outras teóricas pedagógicas, pode nos levar a este projeto em construção, visando à educação de uma sociedade em prol da emancipação do ser humano. Sendo assim: "[...] o trabalho educativo é o ato de produzir direta e intencionalmente em cada indivíduo singular a humanidade que é produzida coletivamente pelo conjunto de homens" (SAVIANI, 2013a, p.13). O singular nos remete à compreensão de

[...] que cada ser é único, que possui características próprias, que aprende diferente em tempo diferente, mas ao mesmo tempo ele faz parte da sociedade e produz juntamente com os demais singulares a história e a cultura do seu povo, então todos precisam participar efetivamente da educação para buscar compreender 0 mundo a sua volta, modificá-lo, se libertando assim dos padrões estabelecidos pela sociedade (SIMÕES, 2015, p.15).

Saviani (2008) afirma que "[...] a essência humana não é, então, dada ao homem; não é uma dádiva divina ou natural; não é algo que precede a existência do homem. Ao contrário, a essência humana é produzida pelos próprios homens" (SAVIANI, 2013b, p.104). Nesse sentido, pensando de forma crítico-dialética, a PHC coloca: se o que está em voga é transformar os homens em humanos, ele só se torna culturalmente humano por meio da educação, que possibilita transformar vidas biológicas em vidas socioculturais.

Diante desta teoria e argumentação, um fundamento essencial é o método de ensino, o qual, para Saviani (2008), se inicia na prática social e a ela retorna em outro patamar de conhecimento. Para tanto, o trabalho educativo apresenta três fases: a problematização, que envolve identificar os problemas da sociedade; a instrumentalização, que permite levantar os instrumentos teórico-práticos para compreendê-los e solucioná-los; e, por fim, a catarse, na qual os elementos são incorporados na vida do estudante, voltando, assim, à pratica social final. 
Tal método tem fundamento na Psicologia Histórico-Cultural de Vygotsky (1997) e seguidores. Concebida com base no Materialismo Histórico-Dialético, formula princípios metodológicos que lhe conferem sustentação na explicação acerca da forma como os sujeitos se apropriam e produzem conhecimentos, formulando novas sínteses (LORENZINI, 2013).

E essa apropriação, por parte dos estudantes, acontece quando "[...] professores, alunos, conteúdos e metodologias se afinam a um dado propósito, a uma concepção de homem e de sociedade, de educação e escolarização" (BARROCO, 2011, p.173). Já sobre a educação dos estudantes com deficiência, a autora afirma de forma mais direta:

[...] os trabalhos de Vygotsky e de outros autores russos e soviéticos constituemse em marcos históricos para a educação especial soviética e não soviética, por enfatizarem que todas as pessoas, inclusive as surdo-cegas [...] (acrescento aqui as demais particularidades) podem beneficiar-se da educação e se desenvolver na mesma direção das pessoas ditas normais, isto é, rumo à formação históricocultural de seus psiquismos. Tal formação se dá por meio da relação intensa e dinâmica com o mundo exterior, o que movimenta e direciona o desenvolvimento das funções psicológicas superiores. Tal relação se apoia na apropriação dos conhecimentos cotidianos e científicos já elaborados e no desenvolvimento e emprego do pensamento e da linguagem verbal (BARROCO, 2011, p.187).

Essa afirmação nos faz refletir sobre o trabalho educativo, e a autora nos chama atenção de que, estando em espaços sociais amplos ou em ambientes educativos, as pessoas com deficiência estão imbricadas pelas determinações da sociedade, presentes numa dinâmica entre a alienação e a liberdade, tanto quanto as pessoas sem deficiência.

Dentre outras teorias pedagógicas do campo específico, nos aproximamos da perspectiva da EF Crítico-Superadora (EFCS), que, alinhada à PHC, objetiva oferecer aos professores um referencial teórico-metodológico capaz de orientar uma prática docente comprometida com o processo de transformação social, tendo como objeto de estudo a cultura corporal que é socialmente construída, como: a dança, a luta, a ginástica, o jogo, o esporte, dentre outras (SOARES et al., 2009).

Para tanto, a aula na Perspectiva da EFCS se desenvolve a partir de momentos metodológicos ou fases:

Uma primeira, onde os conteúdos e objetivos da unidade são discutidos com os alunos, buscando as melhores formas de estes se organizarem para a execução das atividades propostas; uma segunda fase, que toma o maior tempo disponível, refere-se à apreensão do conhecimento; finalmente uma terceira fase, onde se amarram conclusões, avalia-se o realizado e levantam-se perspectivas para as aulas seguintes (SOARES et al., 2009, p.87).

Observa-se que, nas três fases do desenvolvimento da aula, parte-se da prática social e retorna-se a ela, com apoio em Saviani (2011). Logo, a prática social é constante e fundamental para o desenvolvimento de sujeitos críticos. Assim,

[...] os conteúdos da cultura corporal a serem compreendidos na escola devem emergir da realidade dinâmica e concreta do mundo do aluno. Tendo em vista uma nova compreensão dessa realidade social, um novo entendimento que supere 0 senso comum, o professor orientará, através de ciclos, uma nova leitura de realidade pelo aluno, com referências cada vez mais amplas (SOARES et al., 2009, p. 85).

A apropriação da realidade social e, sobretudo, a construção de novas referências, se dará de maneira distinta para cada estudante ao elaborar seu pensamento sobre o conhecimento 
estudado, apresentando ou não uma deficiência e o professor deverá estar atento para isso, respeitando os seus limites e possibilidades.

Isto posto, sustentamos que o objetivo desta investigação consistiu em analisar 0 trabalho educativo nas aulas de EF, discutindo-o na sua relação com os propósitos da inclusão de estudantes com deficiência numa escola regular privada com a base teórica crítico-dialética. Assim, mesmo reconhecendo que outras teorias pedagógicas gerais da educação e específicas da EF podem acumular contribuições acerca da educação inclusiva, delimitamos nosso foco e campo empírico a partir desta particularidade, principalmente por se tratar de um estudo de caso.

\section{METODOLOGIA DA PESQUISA}

Para manter a coerência com as teorias pedagógicas citadas, nos aproximamos, no aspecto metodológico, do Materialismo Histórico-Dialético (MHD), como base teórica que sustenta o estudo, valendo-nos do Método da "ascensão do abstrato ao concreto" elaborado por Kosik (2011) para análise dos dados levantados ao longo do trabalho. $O$ alinhamento do referencial teórico parte da apropriação da matéria que já existe e está mais desenvolvida e, no campo, o caminho do abstrato ao concreto se inicia em uma compreensão da realidade imediata baseada nos conhecimentos do senso comum, "[...] de uma apreensão fenomênica do real, sua materialidade imediata do real; [...] porém, essa apreensão fenomênica do real (a aparência) não corresponde à verdade" (HUNGARO, 2014, p. 70). É preciso chegar à verdade, à essência, através de articulações científicas e filosóficas (KOSIK, 2011).

Em síntese, no método científico em questão, para alcançarmos a essência do fenômeno, exige-se um caminho (détour) metodológico a ser seguido:

\section{1-Minunciosa apropriação da matéria, pleno domínio do material, nele incluídos todos os detalhes históricos aplicáveis, disponíveis; 2- Análise de cada forma do desenvolvimento do próprio material; 3- Investigação da coerência interna, isto é, determinação da unidade das várias formas de desenvolvimento [...] (KOSIK, 2011, p. 37).}

A apropriação da matéria se deu a partir de uma pesquisa bibliográfica, documental e de campo para um aprofundamento teórico sobre as determinações do objeto estudado. Foram estudados o Projeto Político Pedagógico (PPP) ${ }^{1}$, os planejamentos da professora de EF e perfis das turmas sob a sua regência, fornecidos pela escola. Para o campo, realizamos observações, assumindo o papel de "Participante como Observador", ou seja, ao observar, os sujeitos investigados não sabiam quais eram os pontos que estavam sendo considerados, e realizamos, ainda, entrevistas semiestruturadas com as profissionais que interagiam diretamente com a turma investigada (Professora, Coordenadora, Psicóloga e Diretora), a fim de nos apropriarmos de maneira aprofundada da realidade. Utilizamos distintos roteiros nas entrevistas, adaptados diante da função dos sujeitos, entretanto, as questões giraram em torno da educação inclusiva, perguntando sobre formação e experiência, entendimento, base teórica e abordagem metodológica, planejamento, currículo/objetivo/materiais, participação dos estudantes na aula, avaliação, dificuldades para lidar com a educação inclusiva.

Partimos para análise das informações coletadas no levantamento bibliográfico, documental, entrevistas e observações, relacionando-as com as categorias do MHD. Em

$\overline{10}$ Projeto Político Pedagógico (PPP) é um documento de planejamento utilizado pelos pesquisadores restrito ao grupo de trabalho da escola. 
relação a isso, Minayo (1998, p.94) explicita que "[...] para o marxismo as categorias não são entidades, são construídas através do desenvolvimento do conhecimento e da prática social". São conceitos relevantes da realidade histórica, são fundamentais para abordagem que trata das relações dos homens entre si e com a natureza. Nesta mesma vertente teórica, Lorenzini (2013, p. 27) argumenta que

[...] a utilização de categorias, a compreensão da lógica e da teoria do conhecimento são referências fundamentais à qualidade da produção científica. No marxismo o movimento das categorias surge como ato de produção real expressando aspectos fundamentais das relações dos homens entre si e com a natureza sendo construídas através do desenvolvimento do conhecimento e da prática social.

Nesta pesquisa, as categorias totalidade concreta, contradição, realidade e possibilidades perpassam o texto de maneira articulada, pois se constituem dialeticamente de forma indissociável.

Para nos afastarmos do fenômeno imediato, visando atingir a essência, buscamos apreender a realidade concreta, no nosso caso, a fim de compreendermos como se dá a realidade das aulas de EF, particularmente com uma turma que também atendeu estudantes com deficiência e, por isso, investigamos uma escola da cidade do Recife, com um estudo de caso (ARAÚJO et al., 2008).

A escolha da escola se deu por alguns motivos. Um é a sua origem, que data do início da década de 1980, com atendimento pedagógico individualizado à "educação especial". É uma instituição, desde a fundação, demarcada por ideias e ações de uma escola inclusiva. Declara-se com fundamentos socio-históricos para o desenvolvimento das aprendizagens e na especificidade se aproxima da perspectiva da EFCS. E, por fim, pelo vínculo de um dos pesquisadores com a escola, tendo sido estudante durante a formação básica e ainda ter sido docente da instituição por três anos, tendo, portanto, naquele ambiente, o seu primeiro contato com as mais variadas deficiências.

A turma observada foi um $5^{\circ}$ ano do ensino fundamental, selecionada por alguns fatores, a saber: a quantidade de crianças com deficiência; tipos de adequações necessárias; dias da semana em que ocorreriam as aulas. A partir desses critérios, ficou determinada a observação do $5^{\circ}$ ano $D$, nas terças e quintas-feiras, turma de 21 estudantes, tendo três que precisavam de adequações nas aulas de EF, a fim de ser garantida a sua participação nas ações e reflexões tratadas mediante orientação da professora de EF e da solidariedade dos colegas.

Nisto, o trabalho educativo incorporou a realidade dos três estudantes especiais: um com transtorno global do desenvolvimento (TGD), mais especificamente Transtorno do Espectro Autista (Estudante 1); outro surdo com implante coclear (Estudante 2); e o último com síndrome de Pallister-Killian² (Estudante 3). Todos com idades variando entre 10 e 14 anos.

Após a delimitação da turma, foram definidos os sujeitos que responderiam às entrevistas, sendo a diretora detentora do título de mestre, e a professora, a psicóloga e coordenadora com 0 título de especialista. A coordenadora e a professora têm mais de dez anos de vínculo com a escola e a diretora é uma das fundadoras da instituição criada em 1982.

2 Não é nosso propósito definir/conceituar a síndrome, a deficiência auditiva e o transtorno do espectro autista, mas elencar as contribuições pedagógicas possíveis para a participação e aprendizagens dos referidos estudantes mediante a prática pedagógica da professora de Educação Física. 


\section{ANÁLISE E DISCUSSÃO DOS RESULTADOS}

No geral, segundo o PPP (2014) da instituição campo de pesquisa, 10\% dos estudantes eram "portadores de necessidades educacionais especiais" (termo utilizado pela escola):

\section{[...] por apresentarem dificuldades de aprendizagem em uma ou mais áreas do conhecimento ou defasagens em aspectos do seu desenvolvimento, diferenciando- se no nível de apropriação de conhecimentos e/ou de desempenho. Estas dificuldades podem ter caráter permanente ou circunstancial (PPP, p.8).}

O documento revelou que a escola se baseava nas pedagogias do aprender a aprender para desenvolver suas ações, denominando-se socioconstrutivista por associar a Psicologia Genética de Piaget com a Psicologia Histórico-Cultural de Vygotsky.

Este tipo de associação foi criticado por Duarte (2001), por apresentar bases teóricas e concepções de sociedade distintas. Para o referido autor, Vygotsky considera que as perspectivas, tanto da Psicanálise, como de Piaget, caracterizam-se como idealistas, porque abordam o pensamento humano de maneira desvinculada do processo histórico-social de desenvolvimento do pensamento (DUARTE, 2001, p.235).

O PPP da escola afirmou que, a EF trabalhava com a perspectiva Crítico-Superadora, alegando que,

[...] ela incorpora outras propostas, superando-as na medida que nos permite compreender a EF enquanto disciplina curricular, capaz de contribuir com seus conhecimentos para a ampliação da capacidade de reflexão/formação do aluno em sua totalidade, e não unilateralmente (PPP, p.74).

Como a EFCS está fundamentada no MHD, nos deparamos com um problema: se a escola se baseia no socioconstrutivismo e, portanto, nessa associação teórica das pedagogias "do aprender a aprender", como é possível ter espaço para a EFCS que adota um referencial crítico-dialético?

Consideramos que isso se dá pela relação entre orientação geral da escola e incorporação teórica particular das disciplinas, abrindo espaço para os profissionais atuarem de maneira a incorporar por superação o referencial do PPP da escola. Nisto verificamos que, nos documentos da EFCS, ela fundamentou-se no referencial de Vygotsky e seguidores, contribuindo com superações teórico-metodológicas.

Na particularidade da entrevista semiestruturada, a professora de EF, ao ser questionada quanto à base teórica em suas aulas, afirmou que "[...] a abordagem teórica é a que a escola em geral aborda. Que vai para Vygotsky, vai para Piaget. Dessa parte do trabalho com a educação especial e a educação regular", (Professora). Assim evidenciou conhecer aquilo que a escola defende em seu PPP sobre o referencial teórico, mas não argumentou sobre a base teórico-metodológica da EFCS.

Porém, durante as aulas, verificamos que os momentos metodológicos para o ensino dos conteúdos se aproximam da EFCS, contextualizando o conteúdo, confrontando saberes, adequando 0 conhecimento às possibilidades cognoscitivas dos estudantes. Verificamos a consideração das possibilidades e realidades dos estudantes, principalmente, no trato com os objetivos desse componente curricular,

Participar com segurança e autonomia de diferentes atividades corporais, reconhecendo seus limites e valorizando, no sentido de ampliar, suas 
possibilidades pessoais de desempenhos, reconhecendo o sentido e o significado de suas aprendizagens na área da cultura corporal [...] (PPP, p.75).

Entendemos que reconhecer e valorizar a realidade e as possibilidades individuais e buscar a conscientização do estudante quanto ao seu papel na sociedade são referências da EFCS e da PHC como um todo e pode ser o foco principal do ensino que se pretende acolhedor das diferenças, das adequações e flexibilidades.

$\mathrm{Na}$ singularidade da turma investigada, de maneira geral, os Estudantes 1 e 3 não participavam ativamente da discussão inicial da aula quando as conversas costumavam demorar, ficando os dois quietos e distraídos (principalmente o Estudante 1). A sua dificuldade de compreensão quanto ao objetivo e conteúdo da aula levava a professora a chamar a atenção: "Estudante 1, olha pra mim!" (Professora, aula 2). Por conta da restrita participação desses dois estudantes na discussão inicial da aula, a professora precisava explicar novamente, para 0 Estudante 1, o que deveria ser feito adequando a linguagem à compreensão deles.

Entretanto, chamar a atenção de um estudante, ou mesmo de toda a turma, não é suficiente, sendo também necessário se aproximar, explicar, problematizar o que se faz, para que eles percebam um ambiente solícito ou desafiador à sua participação. Assim os estudantes poderão atribuir sentido e significado aos conteúdos da aula, objetivando ampliar sua forma de compreensão da realidade concreta. Esta nos remete ao fato de que "[... ] a visão de totalidade do estudante se constrói à medida que ele faz uma síntese, no seu pensamento, da contribuição das diferentes ciências para a explicação da realidade" (SOARES et al., 2009, p.30).

Segundo os referidos autores, é a partir da sistematização do conhecimento que os estudantes conseguirão "constatar, interpretar, compreender e explicar a realidade social complexa" (SOARES et al., 2009, p.30). Essa sistematização se dará de maneira singular em cada indivíduo, o qual compreende a realidade à sua volta, produzindo suas sínteses diante de suas possibilidades, mas também diante do que a problematização pode lhe desafiar e ir adiante.

Sentimos falta dos questionamentos, por parte da professora, com os Estudantes 1, 2 e 3, em relação aos conteúdos que estavam sendo sistematizados, tanto durante as práticas corporais, quanto durante a síntese final que visava verificar se o objetivo foi atingido ou não. Verificamos que nas Aulas 2, 3, 6, 7, 8, 9 o objetivo foi parcialmente atingido e os conteúdos foram apenas vivenciados, não sendo experimentados, compreendidos, explicados pelos discentes. Evidenciamos que os Estudantes 1, 2 e 3 participaram, mas não chegaram a dar o "salto qualitativo" (SOARES et al., 2009) em relação aos conhecimentos que a EFCS sistematiza, pois esta perspectiva visa à apropriação da realidade em sua totalidade para seguir elaborando novas sínteses.

Por outro lado, nos momentos em que a professora questionou os estudantes com deficiência sobre o conteúdo das aulas, notou-se uma mudança na apropriação da prática corporal. A fala abaixo, utilizada pela professora ao perceber que o Estudante 1 não havia compreendido o significado de atacar e defender durante o jogo, o levou a mudar a forma de agir: "Estudante 1, você precisa proteger esse cone, não pode deixar ninguém chegar perto!" (Professora, Aula 4).

A professora se valeu do momento final da aula para questionar conteúdo e atitudes, elencando pontos que achou relevantes, mas priorizou a verbalização para discutir questões 
sobre a participação dos Estudantes 1, 2 e 3, dizendo: "Gente, vocês precisam lembrar de colocar o Estudante 1 no jogo, bota ele pra bater o lateral, chamem ele pra quadra, ele precisa participar também" (Professora aula 2). Ela ainda destacou questões acerca da participação, como: "[...] na maioria das vezes, só passava quando eu pedia. Vejam, é um jogo coletivo, não pode pensar só em mim, tenho que passar para meus colegas e criar estratégia de jogo que é passar para os colegas" (Professora, aula 5).

Inferimos que o trabalho educativo incluiu os Estudantes 1, 2 e 3 nas aulas, permitindo sua participação nas atividades. Entretanto, a aprendizagem do significado central do jogo requer uma adequação da aula para eles, especificamente mais tempo para a referida apropriação do conhecimento. Destacamos também que a fragilidade na problematização do conteúdo dificultou o desenvolvimento de indivíduos capazes de atuar criticamente na sociedade, pois, quando não se problematiza, a aula se constitui apenas na prática pela prática, sem que os estudantes se apropriem dos sentidos e significados dessas práticas.

Ao analisar o PPP da escola, percebemos a adequação curricular, definida pela escola como:

[...] ajustes ou modificações que deverão ocorrer nos objetivos, conteúdos, critérios de avaliação, temporalidade ou nas atividades de ensino-aprendizagem, para atender à diversidade de alunos que apresentam necessidades educacionais especiais (PPP, p.10).

O argumento do PPP revela orientações para a inclusão escolar, e reconhecemos que, na escola investigada, as adequações tanto podem ocorrer na rotina da sala de aula, com a ajuda pedagógica, como na gestão escolar. A referida questão foi uma temática recorrente durante as entrevistas. A coordenadora aponta que elas constituem o ponto de partida de toda ação pedagógica e são voltadas aos estudantes com deficiência, já que as adequações podem surgir ao longo da prática, de acordo com as necessidades dos estudantes da escola em questão.

\begin{abstract}
A gente começa com um currículo. Com as metas. A gente constrói um currículo adaptado. E depois a partir desse currículo a gente faz o planejamento, nos nossos planos colocamos também as adaptações, o que é que a gente vai fazer de diferente para aquela determinada criança. Tem também a questão dos materiais, dos livros, das fichas também são adaptadas, os livros também podem ser adaptados [...] (Coordenadora).
\end{abstract}

Vê-se que a coordenadora fala em adaptação com o sentido das adequações que podem ser feitas, tanto no currículo quanto nos materiais utilizados em aula. Já no referencial da EFCS, os objetivos e conteúdo não são adaptados, mas são adequados às possibilidades sociocognoscitivas do estudante, ou seja, necessitam ser adequados à capacidade cognoscitiva e à prática social, ao conhecimento e às suas possibilidades enquanto sujeito histórico.

Mittler (2003) considera como parte fundante da educação inclusiva as diferenciações no currículo e nas atividades de aula para lidar com a individualidade, que está diretamente relacionada com a flexibilização das estratégias de ensino. Essas adequações variaram e devem variar de acordo com as singularidades dos estudantes e podem ser elaboradas ao longo do processo educativo, na medida em que as dificuldades vão surgindo. Sobre adequações, as entrevistadas afirmaram: interferência da gente, enquanto que com um menino (usado no genérico) a gente 
ia só uma vez junto, pra ele a gente precisava ir dez vezes junto. Então, o que mudou foi a intervenção da gente, a gente reduziu metas, a gente simplificou os desafios curriculares [...] (Diretora).

[...] dependendo da conversa, eu tenho que fazer uma adaptação, descubro junto com as psicólogas, com a professora que tá mais tempo com a criança, descubro, por exemplo, uma atividade que não vai atingir ela, eu tenho que mudar e acabo mudando essa atividade junto com a professora. Junto com a coordenação [...] (Professora de EF).

A professora e a diretora falam das diferentes formas de adequação. Porém, o que merece destaque é a necessidade de os Estudantes 1, 2 e 3 participarem das discussões juntamente com os demais colegas. Isto não acontecendo, tem por consequência a dificuldade de apropriação da realidade concreta, mesmo que eles não atinjam o grau de profundidade que um estudante sem deficiência alcançaria.

A fala da professora supracitada destaca a necessidade de conhecer o estudante primeiro para depois então decidir se é necessário fazer alguma alteração na sua metodologia de ensino ou no próprio currículo. Em seguida, ela fala da parceria com a coordenação para realizar as adequações. $\mathrm{O}$ que fica claro é que o processo é constante e nunca está pronto. Ele vai sendo elaborado de acordo com as características dos estudantes e das repostas que vão dando ao longo do trabalho educativo.

Em se tratando da elaboração do currículo e dos planejamentos das aulas, percebemos que as mudanças realizadas em aula para atender às necessidades dos educandos variaram de acordo com as suas características. Para o Estudante 2, a professora utilizou metas, passando a falar pausadamente para que esse estudante pudesse entender melhor.

A mudança de atitudes dos professores, quando confrontada com estudantes com deficiência, é uma das dificuldades encontradas para o desenvolvimento de propostas educacionais que se pretendem gradativamente inclusivas (OLIVEIRA et al., 2012), sendo, portanto, fundamental para o desenvolvimento de uma educação mais justa e igualitária. Essa mudança trata, sobretudo, de reconhecer e respeitar as singularidades de cada sujeito e a sua capacidade de explicar a realidade.

Para os Estudantes 1 e 3, a professora sentiu a necessidade de adequar as metas, levando em conta o planejamento para a sala como um todo.

Quadro 1 - Metas presentes no Plano para a sala comum e para os Estudantes 1 e 3.

\begin{tabular}{|c|c|c|}
\hline METAS DA SALA & ESTUDANTE 1 & ESTUDANTE 3 \\
\hline $\begin{array}{c}\text { Aplicar princípios de pensamento } \\
\text { tático estratégico que garantam a } \\
\text { organização coletiva na vivência dos } \\
\text { esportes coletivos. }\end{array}$ & $\begin{array}{c}\text { Participar de diferentes jogos e } \\
\text { esportes coletivos, interagindo } \\
\text { com seus colegas. }\end{array}$ & $\begin{array}{c}\text { Participar de diferentes jogos } \\
\text { coletivos, interagindo com seus } \\
\text { colegas e respeitando seus limites. }\end{array}$ \\
\hline $\begin{array}{c}\text { Pesquisar brinquedos e brincadeiras } \\
\text { existentes em diferentes culturas, } \\
\text { demonstrando-os e vivenciando-os } \\
\text { coletivamente. }\end{array}$ & $\begin{array}{c}\text { Pesquisar brinquedos e } \\
\text { brincadeiras existentes } \\
\text { em diferentes culturas, } \\
\text { demonstrando-os e } \\
\text { vivenciando-os coletivamente. }\end{array}$ & $\begin{array}{c}\text { Pesquisar brinquedos e } \\
\text { brincadeiras existentes em } \\
\text { diferentes culturas, demonstrando- } \\
\text { os e vivenciando-os coletivamente. }\end{array}$ \\
\hline $\begin{array}{c}\text { Discutir e aplicar diferentes ações } \\
\text { táticas e estratégias próprias do jogo. }\end{array}$ & $\begin{array}{c}\text { Discutir e aplicar diferentes ações } \\
\text { táticas e estratégias próprias do } \\
\text { jogo. }\end{array}$ \\
\hline
\end{tabular}


Em relação à adequação das metas, o que nos chamou atenção é que, para o Estudante 1, exigiu-se mais da sua interação e participação nas atividades, pois, sendo um estudante com espectro autista, esta era a sua maior dificuldade. Já para o Estudante 3, as metas já exigiam dele um grau maior de explicação e análise do que deveria ser feito em cada atividade. Além das metas, cada atividade foi adequada para que os estudantes com deficiência pudessem participar de maneira mais ativa das aulas, assim como todos os demais estudantes fossem desafiados perante a inclusão de todos. Como, por exemplo, "[...] na vez do Estudante 1 sacar, quem está ajudando tem que levá-lo próximo da rede para sacar e lembrá-lo que ele pode sacar com as duas mãos" (Professora, aula 9).

A ação favorece a aprendizagem do saque, mesmo que este seja realizado de maneira diferente. Já no jogo do futsal, os Estudantes 1 e 3 jogaram como um a mais, o que favoreceu a aprendizagem coletiva. Essas mudanças na atividade são fundamentais para que os estudantes consigam atingir os objetivos propostos para a aula (STAINBACK; STAINBACK, 1999).

Os estudantes sem deficiência dessa turma mostraram-se familiarizados e solidários com a presença dos deficientes. Exemplo disso é que, nos momentos iniciais da aula, quando ainda estavam dispersos pela quadra, brincando entre si, em diversas ocasiões, os colegas se aproximavam dos Estudantes 1, 2 e 3 para brincarem com eles. "Estudante 1. Te peguei!" (Colega 2, aula 3). Nesse momento a colega faz carinho no Estudante 1 e diz: "Vem, Estudante 2, vamos brincar de luta" [...] (Colega 2, aula 8). Em outro momento: "Vai Estudante 3, arrasa!" (Colega 5, aula 7). "Vou tentar" (Estudante 3, aula 7). "Pensa que você vai conseguir!" (Colega 6, aula 7).

A interação também serviu para a tomada de consciência do que se passava no jogo. "Você bateu em mim" (Estudante 2). [...] "Isso acontece, Estudante 2, é coisa do jogo, foi sem querer" (colega 5). [...] "Tudo bem!" (Estudante 2, aula 7).

Esse tipo de ação foi bastante incentivado pela professora de EF, que inclusive utilizou diversos momentos para atentar que o processo de tomada de consciência não se dá apenas a partir da problematização/interação com ela, mas também a partir das relações existentes em todo o trabalho educativo e, portanto, faz-se necessária uma ação conjunta e consciente daqueles que fazem parte do processo como um todo.

Sobre isso, Maset (2011) afirma que só é possível lidar com tantas singularidades em uma mesma sala de aula se existir uma cooperação entre as partes integrantes do grupo. 0 que acreditamos ser uma base para a construção do respeito às particularidades humanas e, sobretudo, de atitudes mais solidárias.

Promover o trabalho educativo gradativamente inclusivo não é uma tarefa fácil, porém precisamos lembrar que a preocupação deve ser para além da aprendizagem, formando um sujeito capaz de explicar o que está em sua volta, pois

[...] muitas vezes eles entendem o que eles estão fazendo, [...] o porquê está fazendo aquilo, outros não. Exemplo, um jogo de queimada, tem um aluno que ele fica parado no lugar, ele sabe o que é que eles estão fazendo, mas não sabe o movimento que tem que fazer. Então ele fica parado no meio do grupo, na atividade, mas ele fica parado, um aluno chega para ele, entrega uma bola para ele e diz faça isso e ele vai e faz aquilo [...] (Psicóloga).

O estudante precisa reconhecer seu papel, tanto no jogo como na sociedade, o que torna a tarefa educativa desafiadora, pois se busca superar a formação de indivíduos alienados 
que não relacionam suas aprendizagens com a vida. Para tanto, acreditamos ser necessário trazer a discussão da educação da pessoa com deficiência para um patamar macro, o da participação na sociedade, no mundo do trabalho, fazendo a leitura da realidade existente com todas suas contradições, possibilidades, ou seja, na sua totalidade concreta.

\section{CONSIDERAÇÕES FINAIS}

Ao analisar o trabalho educativo nas aulas da EF, discutindo-a na sua relação com os propósitos da inclusão de estudantes com deficiência na particularidade de uma escola regular privada, elencamos as contribuições, partindo do mais geral para a singularidade investigada.

No geral, ao analisar o processo de adequação do currículo da escola, contando com a participação da Coordenadora, da Psicóloga e da Diretora, foi explicitada a existência de argumentos e orientações teóricas que revelaram uma preocupação articulada com a aprendizagem dos educandos na escola investigada mediante as adequações de objetivos, metas, conteúdos, metodologias, avaliações para cada estudante deficiente investigado e, subsequentemente, gerando mudanças e desafios para a turma como um todo.

$\mathrm{Na}$ singularidade do trabalho educativo, constatou-se que durante as 12 aulas de EF observadas, os Estudantes 1, 2 e 3 participaram juntamente com os demais educandos, sem que houvesse restrição às suas aprendizagens sobre o conteúdo tratado e, sempre que necessário, a professora fez modificações nas atividades para que pudessem aprender, desenvolvendo seu próprio pensamento sobre o conteúdo, mesmo que num patamar distinto em relação à turma investigada.

Entretanto, o trabalho educativo em seis, do total das aulas, teve sua problematização fragilizada, evidenciando limitações na metodologia de ensino implementada, em especial a partir da perspectiva da EFCS, em que problematizar ocupa centralidade. Porém, as adequações fizeram-se presentes, tanto no planejamento da unidade de ensino, quanto nas atividades propostas, com alteração das regras dos jogos, dos materiais utilizados em aula, dos conteúdos e envolvimento dos estudantes.

No presente momento, para pensar e realizar uma EF inclusiva, lançamo-nos a desafios. Nosso engajamento político, nossas atitudes cidadãs e pedagógicas devem reivindicar e favorecer a inclusão, não como mera acomodação individual de alguns sujeitos, nem de ajustes perante os limites reconhecidos de estudantes, mas, sim, como uma problematização coletiva das possibilidades de cada um no contexto social e educativo.

No caso específico da EF, um grande desafio é ir além de uma adequação material, ambiental e metodológica para a vivência das práticas corporais. É preciso desafiar os sujeitos envolvidos perante uma reorganização da aula, de forma que objetivos, conteúdos, métodos e recursos possam ser experimentados, compreendidos e explicados de acordo com os limites e possibilidades pessoais e grupais.

\section{REFERÊNCIAS}

ARAÚJO, Cidália et al. Estudo de Caso. Braga : Universidade do Minho/Instituto de Educação e Psicologia, 2008. 
ARAÚJJO JÚNIOR, Danilo Alves de. Educação Física na escola inclusiva: Estudo de caso de uma escola regular em Salvador, Bahia, Brasil. Corpo, Movimento e Saúde, v. 2, n. 4, p. 13-34, 2012.

BARROCO, Sonia Mari Shima. Pedagogia histórico-crítica, pscicologia histórico-cultural e educação especial: em defesa do desenvolvimento da pessoa com ou sem deficiência. In: MARSIGLIA, Ana Carolina Galvão. Pedagogia Histórico-Crítica $\mathbf{3 0}$ anos. Campinas: Autores Associados, 2011. p. 169-196.

BRITO, Raull Felippe de Almeida; LIMA, João Franco. Educação Física adaptada e inclusão : Desafios encontrados pelos professores de EF no trabalho com alunos com deficiência. Corpo, Movimento e Saúde, v. 2, n. 1, p. 1-12, 2012.

CRUZ, Gilmar de Carvalho. Formação continuada de professores de Educação Física em ambiente escolar inclusivo. 2005. 254 f. Tese (Doutorado) - Programa de Pós-Graduação em Educação Física, UNICAMP, Campinas, 2005.

DUARTE, Newton. Vygotsky e o "aprender a aprender": crítica às apropriações neoliberais e pós-modernas da teoria vygotskyana. Campinas: Autores Associados, 2001.

DUARTE, Newton. Fundamentos da pedagogia histórico-crítica: a formação do ser humano na sociedade comunista como referência para a educação contemporânea. In: MARSIGLIA, Ana Carolina Galvão. Pedagogia Histórico-Crítica 30 anos. Campinas: Autores Associados, 2011. p.7-21.

FALKENBACH, Atos Prinz; LOPES, Elaine Regina. Professores de Educação Física diante da inclusão de alunos com deficiência visual. Pensar a Prática, v. 13, n. 3, p. 1-18, 2010.

FIORINI, Maria Luiza Salzani. Concepção do professor de Educação Física sobre a inclusão do aluno com deficiência. 2011. 143 f. Dissertação (Mestrado) - Programa de Pós-graduação em Educação, Faculdade de Filosofia e Ciências, Universidade Estadual Paulista, Marília, 2011.

HUNGARO, Edson Marcelo. A questão do método na constituição da teoria social de Marx. In: CUNHA, Célio da; SOUZA, José Vieira de; SILVA, Maria Abádia da (Org.). 0 método dilético na pesquisa em educação. Campinas: Autores Associados, 2014. p. 368-382

KOSÍK, Karel. Dialética do Concreto. Rio de Janeiro: Paz e Terra, 2011.

LORENZINI, Ana Rita. Conteúdo e método da Educação Física escolar: contribuições da pedagogia histórico-crítica e da metodologia crítico-superadora no trato com a ginástica. 2013. 268 f. Tese (Doutorado) - Programa de Pós-Graduação em Educação, UFBA, Salvador, 2013.

MASET, Pere Pujolàs. Aulas inclusivas e aprendizagem cooperativa. Educação Inclusiva: dos conceitos às práticas na formação. Lisboa: Instituto Piaget, 2011.

MINAYO, Maria Cecília de Souza. O desafio do Conhecimento. São Paulo:Rio de Janeiro: HUCITEC-ABRASCO, 1998.

MITTLER, Peter. Educação Inclusiva: contextos sociais. Porto Alegre: Artmed, 2003.

OLIVEIRA Jáima Pinheiro de et al. Concepções de professores sobre a temática das chamadas dificuldades de aprendizagem. Revista Brasileira Educação Especial, v. 18, n. 1, p. 93-112, 2012.

SAVIANI, Dermeval. Escola e Democracia. Campinas: Autores Associados, 2008. 
SAVIANI, Dermeval. Histórias das Ideias Pedagógicas no Brasil. Campinas: Autores Associados, 2011.

SAVIANI, Dermeval. Pedagogia Histórico-Crítica: primeiras aproximações. Campinas: Autores Associados, 2013a.

SAVIANI, Dermeval. Aberturas para a histórica da educação: do debate teórico-metodológico no campo da história ao debate sobre a construção do sistema nacional de educação no Brasil. Campinas: Autores Associados, 2013b.

SIMÕES, Anais. Educação Física na perspectiva inclusiva: um estudo em uma escola do Recife. 2015. 109 f. Dissertação (Mestrado) - Programa Associado de Pós-Graduação em Educação Física, UPE/UFPB, Recife, 2015.

SOARES, Carmen Lúncia et al. Metodologia do Ensino de Educação Física. São Paulo: Cortez, 2009.

STAINBACK, Susan.; STAINBACK, Willian. Inclusão: um guia para educadores. Porto Alegre: Artmed, 1999.

VYGOTSKY, Lev Semyonovich. Obras Escogidas V. Madrid: Editorial Pedagógica, 1997. 


\section{Apoio financeiro:}

Coordenação de Aperfeiçoamento de Pessoal de Nível Superior (CAPES).

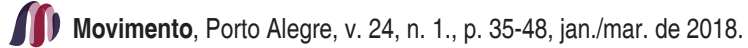

